\title{
Siyatik sinir yaralanmalarında etiyolojik faktörler ile elektrofizyolojik bulguların değerlendirilmesi
}

\author{
Evaluation of etiologic factors and electrophysyologic findings in sciatic nerve injury \\ Pınar Bora Karslı Özgür Zeliha Karaahmet Ece Ünlü Eda Gürçay Fatma Aytül Çakcı
}

Sağıık Bakanlığı Dışkapı Yıldırım Beyazıt Eğitim ve Araştırma Hastanesi, Fiziksel Tıp ve Rehabilitasyon Kliniği, Ankara, Türkiye

\section{Öz}

Amaç: Elektromiyografi (EMG) laboratuvarına başvuran siyatik sinir yaralanmalı hastalarda elektrofizyolojik bulgular eşliğinde etiyolojik faktörlerin incelenmesi hedeflendi.

Gereç ve Yöntem: Bu çalışmada, Ocak 2010 ile Ağustos 2013 tarihleri arasında elektromiyografi (EMG) laboratuvarında incelenen olgular retrospektif olarak incelendi. Standart yöntemlerle sinir ileti ölçümleri ve iğne elektromiyografisi yapılmış olan hastalar çalışmaya alındı. Hasta dosyalarından olgulara ait yaş, cinsiyet, etiyoloji ve öykü ile ilgili veriler elde edildi.

Bulgular: Geriye dönük olarak toplam 3225 olgu tarandı. Siyatik sinir hasarı şüphesiyle EMG laboratuvarına gönderilen olgu sayısı 144 'tü; 50 olguda siyatik sinir hasarı saptandı. Çalışmaya alınan hastaların yaşları 7-88 arasındaydı. Hastaların \%80'i erkek, \%20'si kadındı. Etiyolojik nedenler arasında \%38 ile femur fraktürü ilk sırada yer alırken \%20 ile im enjeksiyonlar ikinci sıradaydı. Vakaların tümünde peroneal sinir hasarı saptandı,\%14'ünde tibial sinirde hasarlanma yoktu. Tibial sinir hasarı olan olguların hepsinde peroneal sinir hasarı bulunuyordu. Peroneal sinir yaralanmalarının \%38'i, tibial sinir yaralanmalarının ise \%18'i total tutulumluydu. En sık neden olarak saptanan kırık etiyolojisinin oranı \%50 idi.

Sonuç: Siyatik nöropatilerin yönetiminde, etiyolojik değerlendirme ve elektrofizyolojik inceleme erken tanı, optimal tedavi ve zamanlama açısından önemli yer tutmaktadır.

Anahtar Sözcükler: Siyatik sinir hasarı, elektromiyografi.

\begin{abstract}
Aim: Our aim is to investigate the etiological factors and electrophysiological findings. of patients with sciatic nerve injury.

Materials and Methods: In the study, the files of the patients who referred to our electromyography (EMG) laboratory at January 2010-August 2013 were retrospectively investigated. Patients whose nerve conduction study and needle EMG were made with standard techniques were included to the study. Age, sex, etiology and history data of the cases from the files were obtained.

Results: A total of 3225 patients were screened retrospectively. The number of cases admitted with the preliminary diagnosis of sciatic nerve injury was 144 and ultimately sciatic nerve lesion was diagnosed in 50 patients. The ages of patients were between $7-88 ; 79.6 \%$ of patients were male and $20.4 \%$ female. Among the etiological factors, femoral fractures ranked first (38\%) and intramuscular injections were second (20\%). In all cases peroneal nerve injury was detected, however there was no damage of tibial nerve in $14 \%$ of the cases. All the patients with tibial nerve lesion was accompanied by the peroneal nerve injury. Also $38 \%$ of peroneal nerve injury and $18 \%$ of tibial nerve lesions were total. Fracture etiology identified as the most frequent cause with $50 \%$ ratio.
\end{abstract}

Conclusion: Etiologic evaluation and electrophysiological studies has an importanat role for the management of sciatic neuropathy in terms of early diagnosis, optimal treatment and timing.

Keywords: Sciatic nerve injury, electromyography.

\footnotetext{
Yazışma Adresi: Özgür Zeliha Karaahmet

Sağlık Bakanlığı Dışkapı Yıldırım Beyazıt Eğitim ve Araştırma

Hastanesi, Fiziksel Tıp ve Rehabilitasyon Kliniği, Ankara, Türkiye

Makalenin Geliş Tarihi: 11.08.2016 Kabul Tarihi: 31.10.2016
} 


\section{Giriş}

Siyatik sinir, insan vücudunda yer alan en uzun ve kesitsel alanı en fazla olan sinirdir. L4-S3'ten köken alır ve büyük siyatik foramenden gluteal bölgeye geçerek, hemen sonra tibial ve peroneal lifler olarak farklılaşır. $N$. peroneus communis daha lateralde seyreder. Peroneal sinir, tibial sinire göre daha oblik bir seyir izler ve tibial sinirden ayrıldıktan sonra yaralanmalara daha açık olacak şekilde yüzeyel seyreder (1-3).

Siyatik sinir lezyonlarının genel olarak en sık nedeni travma olarak bilinmekle birlikte kalça bölgesinde; intramuskuler enjeksiyonlar, penetran travma, kontüzyon, kalça kırığı, cerrahisi ve sinir kompresyonu, uyluk bölgesinde ise; ateşli silah yaralanması (ASY), laserasyon, femur şaft kırığı, kontüzyon, penetran travma ve iyatrojenik yaralanmalar en sık nedenler arasında sayılmaktadır $(4,5)$.

Siyatik sinir lezyonlarında, hamstring kasları ve diz altındaki tüm kaslarda güçsüzlük, tibial ve peroneal sinir dağılımında duyu kaybı olur. Bununla birlikte lateral trunkus daha sıklıkla tutulduğu için peroneal sinir lezyonu ile ayırıcı tanısı yapılmalıdır (5).

Elektrofizyolojik incelemeler lezyon yerinin belirlenmesi, hasarın şiddeti, iyileşme takibi ve ayırıcı tanıda önemli rol oynar $(2,6,7)$. Periferik sinir hasarında prognoz; etiyolojik neden, hasar şiddeti, tipi, hasta yaşı ve hasar seviyesine bağlı olarak değişmektedir $(8,9)$. Bu amaçla siyatik sinir hasarı olduğu düşünülen hastalarda elektrofizyolojik ve etiyolojik faktörlerin değerlendirilmesi hedeflenmiştir.

\section{Gereç ve Yöntem}

Bu retrospektif çalışma, Ocak 2010 ile Ağustos 2013 tarihleri arasında elektromiyografi (EMG) laboratuvarına siyatik sinir yaralanması ön tanısıyla refere edilip, tanı konulan 50 hastanın (40 kadın, 10 erkek) dosyası taranarak yapıldı.

Elektrofizyolojik incelemelerde; diyabetes mellitus, polinöropati, radikülopati, ön boynuz ve pleksus tutulumu olan hastalar çalışmaya dahil edilmedi. Çalışmaya 1-6 ay arasında süre geçmiş ve daha önce ameliyat edilmemiş hastalar dahil edildi.

Hastaların dosyalarından demografik özellikleri; yaş, cinsiyet, meslek, olay süresi ve öyküsü olarak kaydedildi. EMG çalışması aynı fiziyatrist tarafından Medelec Synergy 10 marka elektronöromyografi cihazı ile yapıldı. Standart yöntemlerle sinir ileti ölçümleri ve iğne EMG'si yapılmış olan hastalar çalışmaya alındı.

Verilerin analizi SPSS for IBM 15.0 paket programında yapıldı. Tanımlayıcı istatistikler sürekli değişkenler için ortalama \pm standart sapma veya ortanca (minimummaksimum) olarak, nominal değişkenler sayı ve \% şeklinde gösterildi.

\section{Bulgular}

Geriye dönük olarak toplam 3225 olgu tarandı. Siyatik sinir hasarı şüphesiyle EMG laboratuvarına gönderilen olgu sayısı 144 'tü, 50 olguda siyatik sinir hasarı saptandı. Çalışmaya alınan hastaların yaşları 7-88 arasındaydı. Hastaların demografik özellikleri Tablo-1'de gösterilmektedir.

Tablo-1. Hastaların Demografik Özellikleri.

\begin{tabular}{lc}
\hline & $\mathbf{N}(\%) /($ ort \pm SD) \\
\hline Yaş (yıl) & $45.74 \pm 17.57$ \\
Cinsiyet & \\
Erkek & $40(80.0)$ \\
Kadın & $10(20.0)$ \\
Olay süresi (ay) & $3.25+2.77$ \\
\hline
\end{tabular}

*ort \pm SD: ortalama \pm standart sapma

En sık neden olarak saptanan kırık etiyolojisinin \%50'si trafik kazasına bağlıydı. Diğer kırık nedenleri ise kanser metastazı (\%16.6), yüksekten düşme (\%11.1), bomba patlaması (\%11.1)ve osteoporotik fraktürdü (\%11.1).

Siyatik sinir lezyonu olan hastalarda etiyolojik nedenlerin dağılımına bakıldığında; \%36 ile femur fraktürü ilk sırada yer alırken, \%20 ile im enjeksiyonlar ikinci sıradaydı. Diğer nedenlerin sıklığı ise \%18 ateşli silah yaralanması (ASY), \%14 total kalça protezi (TKP), \%10 kesici alet yaralanması ve \%2'si total diz protezi (TDP) idi (Tablo-2).

Tablo-2. Hastalarda Etiyolojik Faktörlerin Dağııımı.

\begin{tabular}{lc}
\hline Etiyoloji & $\mathbf{N}(\%)$ \\
\hline Femur kırığı & $18(36)$ \\
im enjeksiyon & $10(20)$ \\
Ateşli silah yaralanaması & $9(18)$ \\
Total kalça protezi & $7(14)$ \\
Kesici-delici alet yaralanması & $5(10)$ \\
Total diz protezi & $1(2)$ \\
\hline
\end{tabular}

Vakaların tümünde peroneal sinir hasarı saptandı, \%14'ünde tibial sinirde hasar yoktu (Tablo-3). TDP sonrası nedenli olguların tamamında yalnızca peroneal sinir hasarı görülmüş olup kırığa bağlı olguların \%2'sinde, enjeksiyona bağlı olguların \%1'inde, ASY'ye bağlı olguların \%3'ünde, TKP'ye bağlı olguların \%2'sinde, kesici-delici alet yaralanmalarına bağlı olguların \%4'ünde tibial sinir hasarı saptanmadı.

Tablo-3. Peroneal ve Tibial Sinir Lezyon Şiddeti Dağıımı.

\begin{tabular}{cr}
\hline Lezyon şiddeti & N (\%) \\
\hline Peroneal sinir & \\
Hafif & $5(10)$ \\
Orta & $11(22)$ \\
Ağır & $15(30)$ \\
Total & $19(38)$ \\
Tibial sinir & \\
Hafif & $15(30)$ \\
Orta & $14(28)$ \\
Ağır & $5(10)$ \\
Total & $9(18)$ \\
\hline
\end{tabular}




\section{Tartışma}

Siyatik sinir hasarı olan hastalarda yaralanma tipi, lezyon şiddeti, seviyesi, tutulum şekli gibi etmenler tedavi sürecini etkileyerek, prognozu değiştirdiği için önem arz etmektedir. Bu amaçla çalışmamızda, siyatik sinir lezyonuna neden olan etiyolojik faktörler sorgulanmış, elektrofizyolojik bulgular değerlendirilmiştir.

Yapılan çalışmalarda travmatik periferik sinir yaralanmalarının daha çok erkeklerde ve genç erişkin yaş grubunda görüldüğü bildirilmiş ve buna neden olarak da, bu yaş grubundaki erkeklerin mesleki, sosyal hayatta ve trafikte kadınlara oranla daha aktif olmaları gösterilmiştir (10,11). Ancak, Schmalzried ve ark. (12) tarafından yapılan çalışmada, TKA sonrası sinir lezyonu kadınlarda daha fazla bulunmuştur. Bununla birlikte Pazarcı ve ark. (13) postenjeksiyon nöropatisi ile ilgili yaptıkları çalışmada, çocuklarda cinsiyet oranları benzerken; 60 yaş üstü erkeklerde kadınlara oranla daha fazla siyatik sinir hasarı saptanmıştır. Çalışmamızda ise hasta popülasyonunun büyük çoğunluğu erkeklerden oluşmaktaydı ve yaş ortalaması 45 idi.

Gluteal bölgede, siyatik sinirin kalça eklemine olan yakın komşuluğu nedeniyle bu bölgeye ait fraktür ve cerrahi girişimler gibi kalça ekleminin direkt travması proksimal siyatik sinir nöropatilerinin en sık sebepleridir (14-16). Çalışmamızda da \%36'ık bir oranla femur fraktürü ilk sırada yer almaktaydı.

Siyatik sinir yaralanmalarında, enjeksiyon nöropatisi bir etken olarak gösterilmekle birlikte, çocuklarda, yaşlılarda ve zayıf kişilerde; kas kütlesi ve yağ dokusu daha az olduğu için daha sık karşılaşılmıştır $(1,17-19)$. Bununla birlikte yaralanma intimali, uzun iğne kullanıldığında, iğne sinirin seyrine doğru açılı uygulandığında, hastanın yan yatar pozisyonda yahut ayakta iken yapılan enjeksiyonlarda sinirin yaralanma insidansı artar (20). Kline ve ark. (5) yaptıkları çalışmada im enjeksiyon, kalça seviyesinde siyatik sinir hasarlanmasının en sık nedeni olarak kaydedilmiştir. Enjeksiyona bağlı lezyonlarda hastalar parestezi ve radiküler ağrı şikayetlerinden yakınmakta ve genellikle enjeksiyonun önerilen alanın daha aşağı ve medialinden yapılmasından kaynaklanmaktadır. Çalışmamızda, im enjeksiyona bağlı nöropati sıklığı \%20 olarak bulundu, im enjeksiyon uygulamasının tamamı deneyimli sağlık personeli tarafından, hastane ortamında yapılmış olmasına rağmen büyük oranda görülmesinin sebebi olarak; kişisel farklılıkların ve uygulanan ajanların kimyasal yapısının da hasarlanma konusunda etkili olabileceğini akla getirmektedir

Yapılan çalışmalarda, elektromyografik kayıtlar incelendiğinde; tek başına medial trunkus tutulumunun nadir olduğu, büyük çoğunlukta medial ve lateral trunkus tutulumunun birlikte olduğu veya tek başına ve daha ciddi düzeyde lateral trunkusun tutulumunun olduğu görülmüştür. Lateral trunkusun daha sık etkilenmesinin nedeni olarak; daha büyük fasiküllerden oluşması, destek dokusunun daha az olması, siyatik çentik ve fibula boynu arasında sabitlendiği için gerilmeye eğilimli olduğu belirtilmiştir (21). Literatüre benzer olarak çalışmamızda, hastaların tümünde peroneal sinir hasarı mevcutken, \%14'ünde tibial sinirde hasarlanma yoktu. Tibial sinir hasarı olan olguların hepsinde peroneal sinir hasarı eşlik ediyordu. Peroneal sinir yaralanmalarının $\% 38 ' i$, tibial sinir yaralanmalarının ise $\% 18$ ' $i$ total tutulumluydu.

Noble ve ark. (11) yaptığı bir çalışmada, periferik sinir lezyonlarında total tutulum oranının \%25 olduğu gösterilmiştir. Yapılan bir diğer çalışmada da buna benzer oranlar elde edilmiştir (22). Çalışmamızda ise peroneal sinir yaralanmalarının \%38'i, tibial sinir yaralanmalarının ise \%18'i total tutulumluydu.

Alt ekstremitenin sinir yaralanmaları; hastalarda morbiditeyi arttırarak, fonksiyonellik düzeyindeki sonuçları etkilemektedir. İyileşme üzerine etkili faktörler arasında; etkilenen sinir, lezyonun lokalizasyonu, hasarın büyüklüğü ve tedavi zamanlaması sayılabilir (6).

\section{Sonuç}

Klinik ve elektrofizyolojik olarak siyatik sinir lezyonunun ağırlığı ve etiyolojisi çok değişken olmakla birlikte, enjeksiyon nöropatisi gibi önlenebilir nedenler konusunda ilgili sağlık personeline eğitim verilmeli, bu konudaki kılavuzlar güncellenmelidir. Nöropati oluştuktan sonra ise hastaların yönetiminde; yaratabileceği dizabiliteyi önlemek adına, etiyolojik değerlendirme ve elektrofizyolojik inceleme erken tanı, optimal tedavi ve zamanlama açısından önemli yer tutmaktadır.

\section{Kaynaklar}

1. Moore KL, Dalley AF. Lower limb. Clinically Oriented Anatomy. 4th ed. Baltimore: Lippincott Williams \& Wilkins; 1999:558-9.

2. Burks SS, Levi DJ, Hayes S, Levi AD. Challenges in sciatic nerve repair: Anatomical considerations. J Neurosurg 2014;121(1):210-8

3. Edwards BN, Tullos HS, Noble PC. Contributory factors and etiology of sciatic nerve palsy in total hip arthroplasty. Clin Orthop $1987 ; 218(1): 136-41$

4. Kim DH, Murovic JA, Tiel R, Kline DG. Management and outcomes in 353 surgically treated sciatic nerve lesions. J Neurosurg 2004;101(1):8-17.

5. Kline DG, Kim D, Midha R, Harsh C, Tiel R. Management and results of sciatic nerve injuries: A 24-year experience. J Neurosurg 1998;89(1):13-23. 
6. Igor I, Andrew EP, Israel A, John A IG. Lower Extremity Nerve Trauma. Bull Hosp Jt Dis 2014;72(1):43-52.

7. Aldea PA, Shaw WW. Lower extremity nerve injuries. Clin Plast Surg 1986;13(4):691-9.

8. Taylor CA, Braza D, Rice JB, Dillingham T. The incidence of peripheral nerve injury in extremity trauma. Am J Phys Med Rehabil 2008;87(5):381-5.

9. Uzun N, Tanriverdi T, Savrun FK, et al. Traumatic peripheral nerve injuries: Demographic and electrophysiologic findings of 802 patients from a developing country. J Clin Neuromuscul Dis 2006;7(3):97-103.

10. Kouyoumdjian JA. Peripheral nevre injuries: A retrospective survey of 456 cases. Muscle Nerve 2006;34(6):785-8.

11. Noble J, Munro CA, Prasad VS, Midha R. Analysis of upper and lower extremity peripheral nerve injuries in a population of patients with multiple injuries. J Trauma 1998;45(1):116-22.

12. Schmalzried TP, Noordin S, Amstutz H. Update on nerve palsy associated with total hip replacement. Clin Orthop 1997;344(1):188-206.

13. Pazarcı NK, Orken DN, Çelik MG, Çelebi LG, Aydın Ş. Postenjeksiyon siyatik nöropati: Klinik ve elektrofizyolojik özellikler. Nöropsikiyatri Arşivi 2010;47(1):207-12.

14. Fassler PR, Swiontkowski MF, Kilroy AW, Routt MLJ. Injury of the sciatic nerve associated with acetabuler fracture. J Bone Joint Surg 1993;75(8):1157-66.

15. Yuen EC, Olney RK, So YT. Sciatic neuropathy: Clinical and prognostic features in 73 patients. Neurology 1994;44(1):1669-74.

16. Eser F, Aktekin LA, Bodur H, Atan C. Etiological factors of traumatic peripheral nerve injuries. Neurol India 2009;57(4):434-7.

17. Stewart JD. Focal peripheral neuropathies. Amsterdam: Elsevier; 1987:270-306.

18. Mishra P, Stringer MD. Sciatic nerve injury from intramuscular injection: A persistent and global problem. Int $\mathrm{J}$ Clin Pract 2010;64(1):1573-9.

19. Kim HJ, Park SH. Sciatic nerve injection injury. J Int Med Res 2014;42(4):887-97.

20. Hudson A, Kline D, Gentilli F. Peripheral nerve injection injury. In: Omer GE Jr, Spinner M (ed). 2nd ed. Management of Peripheral Nerve Problems. Philadelphia: WB Saunders; 1980:546-60.

21. Yuen EC, So YT. Sciatic neuropathy. Neurol Clin 1999;17(3):617-31.

22. Bodur H, Uçan H. Periferik sinir yaralanmalı olgularımız. Romatizma 1998;2(1):105-8. 